\title{
Do Patients After Chondrosarcoma Treatment Have Age-appropriate Bone Mineral Density in the Long Term?
}

\author{
Gerhard M. Hobusch MD, Thomas M. Tiefenboeck MD, Janina Patsch MD, \\ Christoph Krall MD, Gerold Holzer MD
}

Received: 25 August 2015/Accepted: 26 January 2016/Published online: 16 February 2016

(c) The Author(s) 2016. This article is published with open access at Springerlink.com

\begin{abstract}
Background In long-term survivors of osteosarcoma and Ewing sarcoma treated with the addition of radio- and chemotherapy, low bone mineral density (BMD) and fractures have been observed, presumably resulting from these adjuvants. Because patients with chondrosarcoma usually are not treated with conventional adjuvant treatment, observation of low BMD in patients with chondrosarcoma presumably would be the result of other
\end{abstract}

Each author certifies that he or she, or a member of his or her immediate family, has no funding or commercial associations (eg, consultancies, stock ownership, equity interest, patent/licensing arrangements, etc) that might pose a conflict of interest in connection with the submitted article.

All ICMJE Conflict of Interest Forms for authors and Clinical Orthopaedics and Related Research ${ }^{\circledR}$ editors and board members are on file with the publication and can be viewed on request.

Clinical Orthopaedics and Related Research ${ }^{\mathbb{R}}$ neither advocates nor endorses the use of any treatment, drug, or device. Readers are encouraged to always seek additional information, including FDAapproval status, of any drug or device prior to clinical use.

Each author certifies that his or her institution approved the human protocol for this investigation, that all investigations were conducted in conformity with ethical principles of research, and that informed consent for participation in the study was obtained.

G. M. Hobusch, T. M. Tiefenboeck, G. Holzer ( $\square)$

Department of Orthopaedic Surgery, Medical University of

Vienna, Waehringer Guertel 18-20, 1090 Vienna, Austria

e-mail: gerold.holzer@meduniwien.ac.at

J. Patsch

Department of Neuroradiology and Musculoskeletal Radiology,

Medical University of Vienna, Vienna, Austria

C. Krall

Center for Medical Statistics, Informatics, and Intelligent

Systems, Medical University of Vienna, Vienna, Austria mechanisms. However, BMD in patients with a history of chondrosarcoma has not been well characterized.

Questions/Purposes The aim of our study was to address the following questions: (1) Do long-term survivors of chondrosarcoma have normal BMD and, if not, which factors contribute to low BMD? (2) Is there a greater risk of fracture and does the Fracture Risk Assessment Tool $\left(\right.$ FRAX $\left.^{\mathbb{R}}\right)$ score reflect fracture likelihood?

Methods All known patients with a history of chondrosarcoma treated at our institution before 2006 were identified. Of 127 patients believed to be alive at the time of this study, 30 agreed to participate in this study (11 females, 19 males; mean age at surgery, $39 \pm 12$ years; mean followup, $12 \pm 5$ years). With the data available, the 30 participants were not different from the 97 nonparticipants in terms of age, sex, BMI, tumor grade, tumor location (axial versus appendicular, lower extremity versus elsewhere), and use of any treatment known to influence osteopenia (chemotherapy, lower extremity surgery). BMD was measured and history of fractures was assessed using a questionnaire. The patientś BMD measurements in this study were sex- and age-matched with a normative sexand age-categorized reference population reported by Kudlacek et al. Associations were tested by univariate regressions and ANOVAs of all measures of BMD and eligible oncologic and demographic factors.

Results Eighteen of $30(60 \%)$ patients had a pathologic BMD according to the WHO dual-energy x-ray absorptiometry definition, $15(50 \%)$ had osteopenia, and three (10\%) had osteoporosis. T-scores in the study cohort were lower than reference values for the femur neck (mean difference, 0.64; 95\% CI, 0.27-1.01; $\mathrm{p}<0.0015$ ), but not for the spine (mean difference, $0.39 ; 95 \% \mathrm{CI},-0.06$ to $0.84 ; \mathrm{p}=0.09)$. Thirteen patients $(45 \%)$ reported a history of fractures not distinguishing between low and high 
impact. The incidence of fractures was 2.8 greater than expected from a comparison with a published microcensus survey of the Austrian population. No effect of the FRAX ${ }^{\circledR}$ score on fracture risk could be identified $(\mathrm{p}=0.057)$.

Conclusions Long-term survivors of chondrosarcoma appear to be at greater risk for having low BMD develop than the healthy population. Although these results are preliminary and based on a very small sampling of patients, if they can be confirmed in larger studies, BMD assessment by dualenergy x-ray absorptiometry might be considered as these patients are followed posttreatment by sarcoma care units. The reasons for low BMD still must be elucidated.

Level of Evidence Level IV, prognostic study.

\section{Introduction}

Patients with solitary chondrosarcomas, the second most common primary malignant bone tumor, are treated primarily by surgical resection because of lack of response to conventional radio- and chemotherapy [37]. Chemotherapy almost never is used in patients with chondrosarcoma, and radiation rarely is used, other than in patients with tumor recurrence or with marginal resection borders. By contrast, primary malignant bone tumors, including osteosarcoma and Ewing sarcoma, are treated using wide resection and (neo)adjuvant chemotherapy. Despite the advantages of chemo- and radiotherapy to patients' survival, there is growing knowledge of side effects, including osteotoxic ones $[2,13,15,23,34]$. Low bone mineral density (BMD) has been observed in survivors of leukemia [1, 11], osteosarcoma [15, 34], and Ewing sarcoma [13, 34] after receiving chemotherapy. Decreased BMD in patients with bone sarcomas seems to be multifactorial in its genesis, and potential factors other than chemotherapy such as surgical treatment of patients, partial weightbearing periods, and long rehabilitation may contribute to low BMD in patients with bone sarcomas.

Less is known about chondrosarcoma and BMD. Patients with chondrosarcoma usually are not treated with adjuvant treatments, therefore if patients with chondrosarcoma are at risk of having low BMD develop, which to our knowledge has not been studied, this presumably would be the result of other mechanisms. Furthermore, pathologic fractures can occur at the time of presentation $[6,43]$ in chondrosarcomas in approximately $17 \%$ to $18 \%$ of patients $[7,36]$, but it is not known whether fracture risk is greater in patients with chondrosarcoma than in the healthy population, or whether that risk might be attributable to low BMD in patients with chondrosarcoma.

The aim of our study was to address the following questions: (1) Do long-term survivors of chondrosarcoma maintain normal BMD and, if not, which factors contribute to low BMD? (2) Is there a greater risk of fractures and does the Fracture Risk Assessment Tool $\left(\right.$ FRAX $\left.^{\mathbb{R}}\right)$ [18] score reflect fracture likelihood?

\section{Patients and Methods}

Between 1971 and 2006, 249 patients with chondrosarcomas at different locations received a diagnosis and were treated at our department. One hundred eleven of these patients already had died of disease at the time of our study. Eleven patients had received chemotherapy for different reasons and therefore were excluded from this study. The study was approved by the institutional review board (EK 373/2009) and conducted according to the Helsinki Declaration. Informed consent was obtained from all participants before inclusion in the study.

Of the 127 patients who were informed by mail, 30 agreed to participate and were included in the study. This group consisted of 19 men and 11 women with a mean age of 39 years (SD, 12; range, 17-69 years) at the time of surgery and mean followup of 12 years (SD, 5; range, 5-24 years). A questionnaire was used to obtain demographic and clinical data. Oncologic data were taken from the prospective local tumor registry and supplemented by thorough chart reviews. Tumors were histologically graded as G1 to G3 by experienced bone pathologists (MS-K, IA, SL) at our institution. Grade G1 tumors were seen in 19 (63\%) patients, G2 in eight (27\%), and G3 in three (10\%). The differentiation of a G1 chondrosarcoma was done when at least all four criteria (cellularity, matrix changes, binuclearity, and nuclear atypia) were fulfilled. The pathology reports from the treatment of these 30 patients were used in this study.

With the data available, the 30 participants were not different from the 97 nonparticipants, who were lost to followup, in terms of age, sex, BMI, tumor grade, tumor location (axial versus appendicular), and use of any treatment known to influence bone health (lower extremity surgery). In the nonparticipants, there were more lower extremity tumors versus tumors elsewhere (Table 1).

All patients had surgery at our institution. The common surgical approach of limb salvage was an excision or resection of the tumor with or without reconstruction by using a mega-endoprosthesis. Nineteen patients (63\%) either had excisions or resections only, seven (23\%) received an endoprosthetic reconstruction after resection of the tumor (Kotz Modular Femoral Tibial Replacement [KMFTR $\left.{ }^{\circledR}\right]$; Stryker Orthopaedics, Mahwah, NJ, USA), and four (14\%) had an amputation. Resection margins were intralesional in 10 patients, marginal in one, and wide in 19. Tumors were located in the proximal humerus $(n=5)$, 
Table 1. Demographics of survivors with chondrosarcoma according to their DEXA-derived bone mineral density

\begin{tabular}{|c|c|c|c|c|c|c|}
\hline Variable & $\begin{array}{l}\text { Healthy } \\
(\mathrm{n}=12)\end{array}$ & $\begin{array}{l}\text { Osteopenia } \\
(\mathrm{n}=15)\end{array}$ & $\begin{array}{l}\text { Osteoporosis } \\
(\mathrm{n}=3)\end{array}$ & $\begin{array}{l}\text { Study } \\
\text { participants (total) } \\
(\mathrm{n}=30)\end{array}$ & $\begin{array}{l}\text { Patients lost } \\
\text { to followup } \\
(n=97)\end{array}$ & $\mathrm{p}$ value \\
\hline \multicolumn{7}{|l|}{ Demographic } \\
\hline $\operatorname{Sex}(\mathrm{F} / \mathrm{M})$ & $5 / 7$ & $5 / 10$ & $1 / 2$ & $11 / 19$ & $41 / 56$ & 0.67 \\
\hline Age (at time of surgery) ${ }^{\dagger}$ & $34 \pm 9$ & $41 \pm 13$ & $47 \pm 21$ & $39 \pm 13$ & $40(10-86)$ & 0.67 \\
\hline Age (at time of DEXA) ${ }^{\dagger}$ & $46 \pm 11$ & $52 \pm 13$ & $57 \pm 19$ & $51 \pm 13$ & & \\
\hline Followup $^{\dagger}$ & $14 \pm 6$ & $12 \pm 5$ & $11 \pm 3$ & $13 \pm 5$ & & \\
\hline $\operatorname{BMI}\left(\mathrm{kg} / \mathrm{m}^{2}\right)^{\ddagger}$ & $27 \pm 4$ & $26 \pm 5$ & $23 \pm 2$ & $26.2 \pm 5$ & $25.7(17-35)$ & 0.74 \\
\hline Physical functioning (SF-36) & $66 \pm 33$ & $58 \pm 34$ & $77 \pm 20$ & $63 \pm 32$ & & 0.6 \\
\hline \multicolumn{7}{|c|}{ Tumor grade (available for 88 patients; missing for 9 patients) } \\
\hline G1 & 9 & 7 & 3 & 19 & 46 & 0.39 \\
\hline $\mathrm{G} 2$ & 2 & 6 & 0 & 8 & 29 & 1.0 \\
\hline G3 & 1 & 2 & 0 & 3 & 13 & 0.75 \\
\hline Metastasis & 0 & 1 & 0 & 1 & & \\
\hline Local recurrence & 2 & 1 & 0 & 3 & & \\
\hline \multicolumn{7}{|l|}{ Localization of tumor (97 patients) } \\
\hline Tibia/fibula & 2 & 2 & 0 & 4 & 10 & 0.73 \\
\hline Femur & 1 & 2 & 1 & 4 & 23 & 0.3 \\
\hline Pelvis & 1 & 3 & 0 & 4 & 21 & 0.43 \\
\hline Scapula & 2 & 0 & 0 & 2 & 3 & 1.0 \\
\hline Humerus & 3 & 2 & 0 & 5 & 10 & 0.34 \\
\hline Finger & 1 & 2 & 2 & 5 & 23 & 0.64 \\
\hline Ribcage & 1 & 3 & 0 & 4 & 6 & 0.12 \\
\hline Spine & 1 & 1 & 0 & 2 & 1 & 0.13 \\
\hline Axial & & & & 6 & 31 & 0.25 \\
\hline Appendicular (extremities, scapula, and pelvis) & & & & 24 & 66 & 0.25 \\
\hline Lower extremity & & & & 12 & 61 & 0.03 \\
\hline Elsewhere & & & & 18 & 35 & 0.03 \\
\hline \multicolumn{7}{|l|}{ Surgical method } \\
\hline Curettage & 5 & 4 & 2 & 11 & 27 & 0.37 \\
\hline Resection & 4 & 4 & 0 & 8 & 34 & 0.5 \\
\hline Endoprosthetic reconstruction & 3 & 4 & 0 & 7 & 29 & 0.64 \\
\hline Amputation & 0 & 3 & 1 & 4 & 7 & 0.28 \\
\hline Lower extremity surgery & & & & 12 & 61 & 0.03 \\
\hline
\end{tabular}

Ranges are presented in parentheses; ${ }^{\dagger}$ mean in years; ${ }^{*}$ mean; DEXA $=$ dual-energy x-ray absorptiometry; all patients were Caucasian and were free of diabetes, obesity, or other metabolic disorders other than oncologic disease.

proximal femur $(\mathrm{n}=2)$, distal femur $(\mathrm{n}=2)$, pelvis $(\mathrm{n}=4)$, tibia or fibula $(\mathrm{n}=4)$, scapula $(\mathrm{n}=1)$, rib cage $(n=5)$, spine $(n=2)$, and long finger bones $(n=5)$.

\section{Densitometric Technique}

BMD of the lumbar spine (L1-L4) and of the proximal femur (total femur, femoral neck) of the nonoperated side was assessed by dual-energy x-ray absorptiometry (DEXA) (Hologic Discovery $^{\mathrm{TM}}$ A, Hologic Explorer ${ }^{\mathrm{TM}}$; Hologic Inc, Bedford, MA, USA) (S/N 45313; Lunar $^{\circledR}$ Prodigy; GE
Medical Systems, Munich, Germany). BMD results are expressed in terms of SD from a reference population (Tscores) and from a healthy, age- and sex-matched reference population (Z-score). To correct for the different facilities, BMD values were calculated for Lunar ${ }^{\circledR}$ Medical Systems according to Genant et al. [9]. Patients were classified according to the WHO guidelines [35] in three groups: BMD values greater than -1 were considered normal, between -1 and -2.5 were classified as osteopenic, and less than -2.5 were considered osteoporotic [22].

An online fracture risk assessment tool [18] was used to calculate the $\operatorname{FRAX}^{\circledR}$ [21]. 
Table 2. Comparison of the prevalence of osteopenia

\begin{tabular}{|c|c|c|c|c|c|c|c|c|c|c|}
\hline \multirow[t]{2}{*}{ Study } & \multicolumn{10}{|c|}{ Age groups (range in years) } \\
\hline & $20-24$ & $25-29$ & $30-34$ & $35-39$ & $40-44$ & $45-49$ & $50-54$ & $55-59$ & $60-64$ & $65-69$ \\
\hline Current study & $50 \%$ & & $25 \%$ & & $50 \%$ & & $75 \%$ & & $71 \%$ & \\
\hline Looker et al. (NHANES III) [29] & NA & NA & NA & NA & NA & NA & $34 \%-49 \%$ & & & \\
\hline Looker et al. (NHANES 2005-2006) [29] & NA & NA & NA & NA & NA & NA & $32 \%-50 \%$ & & & \\
\hline Guzmán Ibarra et al.* $[10]$ & NA & NA & NA & NA & NA & $18 \%$ & $47 \%$ & $44 \%$ & $64 \%$ & $53 \%$ \\
\hline Larjiani et al.** [27] & $13 \%-17 \%$ & & $8 \%-24 \%$ & & $29 \%-31 \%$ & & $42 \%-46 \%$ & & $47 \%-50 \%$ & \\
\hline
\end{tabular}

* Data presented for womenś incidence of osteopenia; **data presented as lowest and highest value of womenś and menśosteopenia in femur neck and spine; $\mathrm{NA}=$ not available.

\section{Laboratory Examination}

Routine standard laboratory parameters like blood cell counts, electrolytes including serum calcium and phosphate, and bone turnover markers like osteocalcin, bonespecific alkaline phosphatase, parathyroid hormone, $\mathrm{N}$ terminal propeptide of type I collagen, and the crosslinked C-telopeptides of type I collagen, calcitonin, thyroid, and sexual hormones were assessed for all 30 patients.

\section{Physical Function}

All 30 patients had a physical examination and were evaluated according to Enneking et al. [8]. Physical ability was measured by Medical Outcomes Study SF-36 physical functioning subscale $[5,19]$. The validity and reliability of the SF-36 has been established in patients with a history of cancer $[3,33]$.

\section{Normative Data}

We used a published age-, sex-, and area-of-living matched control group for bone status [24]. The patientś BMD measurements in our study were sex- and age-matched and compared by paired t-tests [24]. In addition, the incidence of osteopenia in our study population was compared with incidences reported in other studies (Table 2) [10, 29]. In our most prominent age group of patients (40-49 years), the incidence of osteopenia in men and women was 50\%, whereas according to selected normative data $29 \%$ of $31 \%$ had osteopenia [27].

\section{Statistics}

The patientś BMD measurements in our study were sexand age-matched with normative sex- and age-categorized data [24] and compared by paired t-tests. Univariate regressions of all measures of BMD on BMI, age at diagnosis, age at followup, and period between diagnosis and followup were performed. Correlation between fracture risk and $\mathrm{T}$-scores was analyzed by logistic regression models. One-way ANOVA t-tests of all measures of BMD on sex, surgery, tumor grading, resection margins, and fractures were performed. The T-score depending on the FRAX $^{\circledR}$ was strongly right skewed, therefore this variable was transformed by taking the square root to obtain a more symmetric distribution and improve model fit. Owing to the explorative nature of the study, no correction for multiple hypothesis testing was done. All statistical calculations were performed with R 2.15.2 under R-studio (The R Project for Statistical Computing, Vienna, Austria).

\section{Results}

\section{Bone Mineral Density}

Overall $18(60 \%)$ of the patients showed low BMD values. Three patients (10\%; one female, two males) had osteoporosis, 15 (50\%; five females, 10 males) had osteopenia, and 12 (40\%; five females, seven males) had normal BMD (Table 3). T-scores in the study cohort were less than those of age- and sex-matched reference values for the femoral neck (mean difference, $0.64 ; 95 \% \mathrm{CI}, 0.27-1.01 ; \mathrm{p}=0.0015$ ), but not for the spine (mean difference, $0.39 ; 95 \% \mathrm{CI},-0.06$ to $0.84 ; \mathrm{p}=0.09$ ). Patients with higher BMI had higher Tscores of the lumbar spine $(0.101 ; 95 \% \mathrm{CI}, 0.01-0.19$; $\mathrm{p}=0.031)$, but not of the femoral neck $(0.02 ; 95 \% \mathrm{CI}$, -0.07 to $0.12 ; \mathrm{p}=0.61)$ Age at diagnosis $(-0.04 ; 95 \% \mathrm{CI},-$ 0.07 to $-0.01 ; \mathrm{p}=0.007)$ and age at followup $(-0.37 ; 95 \%$ $\mathrm{CI},-0.07$ to $-0.01 ; \mathrm{p}=0.013)$ showed negative correlations with the T-score of the femoral neck. However, no correlation of T-scores of the lumbar spine was identified for age at diagnosis and for age at followup. The followup period, type of surgery, and physical ability/activity (SF-36 physical functioning) were not associated with T-scores of the femoral neck nor the lumbar spine. Physical ability in 


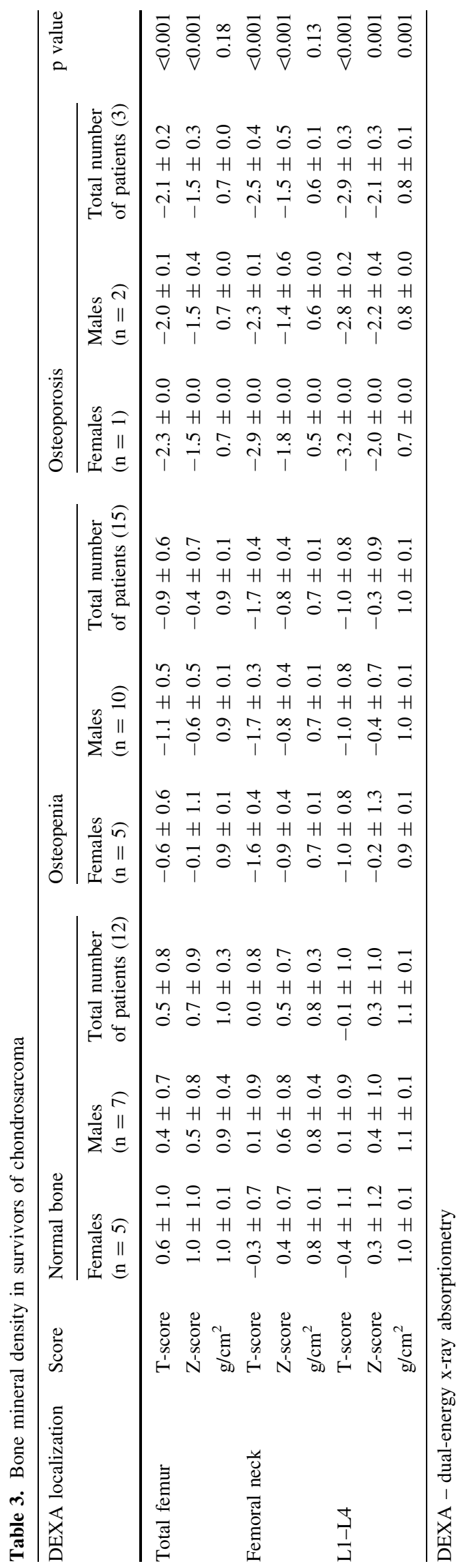

patients who had surgery of the upper limb $(77 \pm 27)$ compared with the lower limb $(60 \pm 27)$ showed no substantial difference (mean difference, $17 ; 95 \% \mathrm{CI},-10$ to 45 ; $\mathrm{p}=0.21$ ). In addition, T-scores of the femoral neck in patients who had upper limb surgery $(-0.99 \pm 1.1)$ and lower limb surgery $(-1.5 \pm 0.78)$ showed no difference (mean difference, $-0.5 ; 95 \% \mathrm{CI},-1.4$ to $0.5 ; \mathrm{p}=0.27$ ).

\section{Fracture Risk}

Thirteen patients reported a history of fractures (45\%). Throughout the study population, the incidence of fractures per year was 0.034. In comparison, incidence rates in the Austrian reference population range between 0.010 and 0.018 fractures per year in the corresponding sex-specific age groups [41]. In an age and sex-matched sample from the population, a total of 4.7 fractures would be expected when accounting for the followup period for each patient. Fractures in the study population were not localized at typical osteoporotic fragility fracture sites (Table 4). BMD expressed by T-scores of the femoral neck (odds ratio [OR], $0.59 ; 95 \% \mathrm{CI}, 0.25-1.21 ; \mathrm{p}=0.181)$ and lumbar spine (OR, 0.86 ; 95\% CI, 0.44-1.62; $\mathrm{p}=0.64$ ) did not show effects on the incidence of fractures. The FRAX ${ }^{\circledR}$ score did not show effects on the incidence of fractures (OR, 2.5; 95\% CI, 0.97-6.54; $\mathrm{p}=0.057$ ). No substantial difference in SF-36 physical function score was seen between patients with fractures $(60 \pm 31)$ and those with no fractures $(66 \pm 33)$ (mean difference, 6; 95\% CI, -19.11 to $31.78 ; \mathrm{p}=0.61$ ).

\section{Discussion}

Chondrosarcoma is the second most-frequent malignant bone tumor. The standard treatment of patients with chondrosarcoma is a wide resection or aggressive curettage for selected low-grade extremity chondrosarcomas only. Although other primary malignant bone tumors like osteosarcoma and Ewing sarcoma are treated with a multidisciplinary approach including chemotherapy and surgical resection, patients with chondrosarcoma do not show any clinical response to conventional adjuvant treatments. Low BMD and increased fracture rates after multimodal treatment of chemosensitive primary bone tumors are presumed to be osteotoxic side effects of chemotherapeutic treatments [2, 13, 15, 23]; however, other risk factors for low BMD in patients with a history of bone tumors may be present. To test the BMD of patients with chondrosarcoma, and because treatment of osteoporosis and osteopenia may be indicated once it is discovered, we wanted to assess whether patients with chondrosarcoma experience low BMD even in the absence of potentially osteotoxic chemotherapeutic treatment. 
Table 4. Fractures in survivors of chondrosarcoma

\begin{tabular}{llll}
\hline Variable & \multicolumn{2}{l}{ Number of fractures (males/females) } & \\
\cline { 2 - 4 } & $\begin{array}{l}\text { Normal BMD } \\
4(4 / 0)\end{array}$ & $\begin{array}{l}\text { Osteopenia } \\
6(3 / 3)\end{array}$ & $\begin{array}{l}\text { Osteoporosis } \\
3(2 / 1)\end{array}$ \\
\hline FRAX $^{\mathbb{R}}$ score (calculation included BMD) & $0.7(0-2)$ & $3.9(1-11)$ & $6.7(4-8)$ \\
Location of fracture & & & $3.5(0-11)$ \\
Hand (carpus, phalanges) & $2(2 / 0)$ & $2(0 / 2)$ & $2(1 / 1)$ \\
Distal radius & & $1(0 / 1)$ & $2(0 / 2)$ \\
Humerus & $1(1 / 0)$ & $2(2 / 0)$ & $1(0 / 1)$ \\
Tibia & $1(1 / 0)$ & $1(1 / 0)$ & $4(4 / 0)$ \\
Femur & & & $1(1 / 0)$ \\
\hline
\end{tabular}

FRAX $^{\mathbb{R}}=$ Fracture Risk Assessment Tool; BMD = bone mineral density.

This study is limited because of the patients assumed to be alive, only $25 \%$ responded and agreed to participate. Survivors of malignant diseases may decline participation in studies for various reasons including general rejection of study participation or owing to professional commitments, not having time for followups, or relocation of residence. This poses a selection bias. However, because our tumor register's demographic and oncologic data for the 97 patients lost to followup, including age, sex, BMI, tumor grade, tumor location (axial versus appendicular), and use of any treatment that could influence osteopenia (eg, chemotherapy), did not differ from the data of our study patients (Table 1), we believe our study patients reasonably represent the population of patients with this condition. However, there were more lower extremity tumors in the 97 nonparticipants, therefore you could argue that, if less mobility plays a role after treatment of lower extremity tumors, which potentially could lead to less BMD, then the nonparticipants would be even more prone to low BMD, and results would be even more powerful.

The tumors varied in size and by site with some lower extremity and some upper extremity lesions. In addition patients had many different types of surgical procedures, which potentially could affect BMD findings. With the small numbers available, we could not show that these issues were statistically related to BMD, but a study of larger groups of patients might show differences. Our patient population includes patients of differing ages, and with low- and highgrade tumors, major resections/reconstructions, and curettage. Our numbers are not large enough to look at differences between a high-grade chondrosarcoma of the lower extremity treated with megaprostheses and a small chondrosarcoma of the finger. Additional study is needed with a larger, more homogeneous population of patients before our findings can be generalized. Finally, our numbers are too small to perform a multivariate analysis to assess which are the most important factors predicting low BMD in the patients with chondrosarcoma; as such, confounding variables may have influenced some of our findings. No-difference findings could be a function of insufficient sample size.

Eighteen $(60 \%)$ of 30 patients in our study had a pathologic BMD. T-scores in the study cohort were lower than reference values for the femoral neck ( $\mathrm{p}<0.001$ ), but not for the spine $(\mathrm{p}=0.11)$. Osteoporosis was seen in four patients. Surgical treatment of patients with bone sarcoma is followed by a long rehabilitation and periods with partial weightbearing. Patients often are restricted in their activities of daily living [32], physical activity [14], and sports activity [12, 25], which may influence BMD because of inactivity [17, 26, 28, 30]. Furthermore, in patients with chondrosarcoma, pathologic fractures occur at presentation of the disease $[6,43]$ in approximately $17 \%$ to $18 \%$ [6] and it is not known whether these patients continue to experience bone events once a chondrosarcoma has been diagnosed. Unlike patients with bone tumors which are treated with chemotherapy and radiation and are known to affect bone density [13, 15, 38], patients with chondrosarcoma generally do not receive these adjuvant treatments. Therefore, the reason for the lowerthan-expected BMDs in patients with chondrosarcoma is not known However, abnormally low BMD in our patients was surprisingly common $(60 \% ; 18$ of 30$)$, and we did not detect any particular predictors of this apart from BMI, which exerted a protective effect. Morin et al. [31] discussed weight and body mass predicting low BMD in women 40 to 59 years old. In line with these data, the most powerful factor indicating low Z-scores of the femoral neck in our study was BMI. However, this appears to be an associated factor in patients with postmenopausal osteoporosis and in patients with a history of chemosensitive malignant bone tumors [13, 38, 40]. Although these long-term data did not reveal a correlation between sex hormones and bone status at the time of followup, there is some evidence that estrogen metabolism may be associated with the occurrence of chondrosarcoma and translational research has validated estrogen signaling a potential antitumor-therapeutic target [7]. Because sex hormones are involved in bone homeostasis as well, there could 
be a possible link. Another possibility is that the BMD findings may be "tumor-induced," that is, related to a factor produced by the tumor, which is seen in certain types of tumors such as myeloma [42]. In these patients bone loss is mediated by various biologic factors produced by osteoblasts or by malignant plasma cells [42]. Tumor-induced bone loss also is seen with metastatic disease [4]. Future studies will need to determine whether there is any such tumor-related factor produced by chondrosarcoma cells.

A total of $45 \%$ of our patients (13 of 30) experienced fractures, and these fractures did not occur at typical osteoporotic fragility fracture sites. Two low-impact radius fractures were reported; the others may be considered highimpact fractures The incidence of fractures in our study population was higher than expected by a factor of 2.8 compared with a microcensus survey of the Austrian population [41]. Low BMD has been shown to be a good predictor for fractures in the elderly [20,39]. Our study did not reveal an effect of low BMD on fractures in patients with a history of chondrosarcoma. There might be other reasons for fractures than low BMD, such as changes of the cortical bone, that cannot be assessed by DEXA [16]. In addition, no correlation between FRAX ${ }^{\circledR}$ score and fracture risk was identified.

Our study showed an abnormal BMD in the majority of patients with chondrosarcoma. Patients with a history of chondrosarcoma appear to have low BMD of the proximal femur develop for reasons yet unknown and might have higher fracture rates than healthy age-related persons. The no-difference findings concerning low BMD in this series regarding age, different surgical techniques, tumor sites, and followup may be the result of insufficient sample size; alternatively, they may represent a yet-to-be defined tumorrelated effect associated with chondrosarcoma, as seen in certain other tumors $[4,42]$. As a consequence, physicians should be aware of the potential for low BMD in patients with chondrosarcoma and should consider evaluation and possible treatment of those with low BMD. Additional studies with larger numbers of patients with chondrosarcoma are necessary to confirm our findings, but our study may serve as a pilot study to further investigate the hypotheses of possible tumor-related bone loss in patients with sarcomas.

Acknowledgments Open access funding provided by Medical University of Vienna. We thank M. Salzer-Kuntschik MD, PhD, I. Aman MD, and S. Lang MD, bone tumor pathologists at our institution, for the pathology reports of all patients included in this study.

Open Access This article is distributed under the terms of the Creative Commons Attribution 4.0 International License (http:// creativecommons.org/licenses/by/4.0/), which permits unrestricted use, distribution, and reproduction in any medium, provided you give appropriate credit to the original author(s) and the source, provide a link to the Creative Commons license, and indicate if changes were made.

\section{References}

1. Arikoski P, Komulainen J, Riikonen P, Voutilainen R, Knip M, Kröger H. Alterations in bone turnover and impaired development of bone mineral density in newly diagnosed children with cancer: a 1-year prospective study. J Clin Endocrinol Metab. 1999;84:3174-3181.

2. Azcona C, Burghard E, Ruza E, Gimeno J, Sierrasesúmaga L. Reduced bone mineralization in adolescent survivors of malignant bone tumors: comparison of quantitative ultrasound and dual-energy x-ray absorptiometry. J Pediatr Hematol Oncol. 2003;25:297-302.

3. Bélanger LJ, Plotnikoff RC, Clark A, Courneya KS. Physical activity and health-related quality of life in young adult cancer survivors: a Canadian provincial survey. J Cancer Surviv. 2011;5:44-53.

4. Berruti A, Dogliotti L, Tucci M, Tarabuzzi R, Fontana D, Angeli A. Metabolic bone disease induced by prostate cancer: rationale for the use of bisphosphonates. J Urol. 2001;166:2023-2031.

5. Brazier JE, Harper R, Jones NM, O'Cathain A, Thomas KJ, Usherwood T, Westlake L. Validating the SF-36 health survey questionnaire: new outcome measure for primary care. $B M J$. 1992;305:160-164.

6. Chandrasekar CR, Grimer RJ, Carter SR, Tillman RM, Abudu AT, Jeys LM. Outcome of pathologic fractures of the proximal femur in nonosteogenic primary bone sarcoma. Eur J Surg Oncol. 2011;37:532-536.

7. Chow WA. Update on chondrosarcomas. Curr Opin Oncol. 2007;19:371-376.

8. Enneking WF, Dunham W, Gebhardt MC, Malawar M, Pritchard DJ. A system for the functional evaluation of reconstructive procedures after surgical treatment of tumors of the musculoskeletal system. Clin Orthop Relat Res. 1993;286:241-246.

9. Genant HK, Grampp S, Glüer CC, Faulkner KG, Jergas M, Engelke K, Hagiwara S, Van Kuijk C. Universal standardization for dual X-ray absorptiometry: patient and phantom cross-calibration results. J Bone Miner Res. 1994;9:1503-1514.

10. Guzmán Ibarra M, Ablanedo Aguirre J, Armijo Delgadillo R, García Ruíz Esparza M. [Prevalence of osteopenia and osteoporosis assessed by densitometry in postmenopausal women] [in Spanish]. Ginecol Obstet Mex. 2003;71:225-232.

11. Henderson RC, Madsen CD, Davis C, Gold SH. Bone density in survivors of childhood malignancies. J Pediatr Hematol Oncol. 1996;18:367-371.

12. Hobusch GM, Lang N, Schuh R, Windhager R, Hofstaetter JG. Do patients with Ewing's sarcoma continue with sports activities after limb salvage surgery of the lower extremity? Clin Orthop Relat Res. 2015;473:839-846.

13. Hobusch GM, Noebauer-Huhmann I, Krall C, Holzer G. Do long term survivors of Ewing family of tumors experience low bone mineral density and increased fracture risk? Clin Orthop Relat Res. 2014;472:3471-3479.

14. Hoffman MC, Mulrooney DA, Steinberger J, Lee J, Baker KS, Ness KK. Deficits in physical function among young childhood cancer survivors. J Clin Oncol. 2013;31:2799-2805.

15. Holzer G, Krepler P, Koschat MA, Grampp S, Dominkus M, Kotz R. Bone mineral density in long-term survivors of highly malignant osteosarcoma. J Bone Joint Surg Br. 2003;85:231-237.

16. Holzer G, von Skrbensky G, Holzer LA, Pichl W. Hip fractures and the contribution of cortical versus trabecular bone to femoral neck strength. J Bone Miner Res. 2009;24:468-474.

17. Inomoto T. [Physical activity/sports and bone mineral density] [in Japanese]. Clin Calcium. 2008;18:1339-1348.

18. Institute for Better Bone Health. FRAX ${ }^{\mathbb{R}} \mid$ Fracture Risk Assessment Tool. Available at: http://www.bonehealthnow.com/cms/ 
FRAXFractureRiskAssessmentTool_74.aspx. Accessed March $25,2015$.

19. Jenkinson C, Coulter A, Wright L. Short form 36 (SF36) health survey questionnaire: normative data for adults of working age. BMJ. 1993;306:1437-1440.

20. Johnell O, Kanis JA, Oden A, Johansson H, De Laet C, Delmas P, Eisman JA, Fujiwara S, Kroger H, Mellstrom D, Meunier PJ, Melton LJ, O'Neill T, Pols H, Reeve J, Silman A, Tenenhouse A. Predictive value of BMD for hip and other fractures. $J$ Bone Miner Res. 2005;20:1185-1194.

21. Kanis JA. Diagnosis of osteoporosis and assessment of fracture risk. Lancet. 2002;359:1929-1936.

22. Kanis JA, Devogelaer JP, Gennari C. Practical guide for the use of bone mineral measurements in the assessment of treatment of osteoporosis: a position paper of the European foundation for osteoporosis and bone disease. The Scientific Advisory Board and the Board of National Societies. Osteoporos Int. 1996;6:256-261.

23. Kaste SC, Ahn H, Liu T, Liu W, Krasin MJ, Hudson MM, Spunt SL. Bone mineral density deficits in pediatric patients treated for sarcoma. Pediatr Blood Cancer. 2008;50:1032-1038.

24. Kudlacek S, Schneider B, Peterlik M, Leb G, Klaushofer K, Weber K, Woloszczuk W, Willvonseder R. Normative data of bone mineral density in an unselected adult Austrian population. Eur J Clin Invest. 2003;33:332-339.

25. Lang NW, Hobusch GM, Funovics PT, Windhager R, Hofstaetter JG. What sports activity levels are achieved in patients with modular tumor endoprostheses of osteosarcoma about the knee? Clin Orthop Relat Res. 2015;473:847-854.

26. Lappe JM, Watson P, Gilsanz V, Hangartner T, Kalkwarf HJ, Oberfield S, Shepherd J, Winer KK, Zemel B. The longitudinal effects of physical activity and dietary calcium on bone mass accrual across stages of pubertal development. J Bone Miner Res. 2015;30:156-164.

27. Larijani B, Hossein-Nezhad A, Mojtahedi A, Pajouhi M, Bastanhagh MH, Soltani A, Mirfezi SZ, Dashti R. Normative data of bone mineral density in healthy population of Tehran, Iran: a cross sectional study. BMC Musculoskelet Disord. 2005;6:38.

28. Lee IM, Wolin KY, Freeman SE, Sattlemair J, Sesso HD. Physical activity and survival after cancer diagnosis in men. $J$ Phys Act Health. 2014;11:85-90.

29. Looker AC, Melton LJ, Harris TB, Borrud LG, Shepherd JA. Prevalence and trends in low femur bone density among older US adults: NHANES 2005-2006 compared with NHANES III. $J$ Bone Miner Res. 2010;25:64-71.

30. Miyahara K, Wang DH, Mori K, Takahashi K, Miyatake N, Wang BL, Takigawa T, Takaki J, Ogino K. Effect of sports activity on bone mineral density in wheelchair athletes. $J$ Bone Miner Metab. 2008;26:101-106.
31. Morin S, Tsang JF, Leslie WD. Weight and body mass index predict bone mineral density and fractures in women aged 40 to 59 years. Osteoporos Int. 2009;20:363-370.

32. Parks R, Rasch EK, Mansky PJ, Oakley F. Differences in activities of daily living performance between long-term pediatric sarcoma survivors and a matched comparison group on standardized testing. Pediatr Blood Cancer. 2009;53:622-628.

33. Pinar R. Reliability and construct validity of the SF-36 in Turkish cancer patients. Qual Life Res. 2005;14:259-264.

34. Pirker-Frühauf UM, Friesenbichler J, Urban EC, Obermayer-Pietsch B, Leithner A. Osteoporosis in children and young adults: a late effect after chemotherapy for bone sarcoma. Clin Orthop Relat Res. 2012;470:2874-2885.

35. Public Health Foundation Enterprises; 4 Bone Health. World Health Organization-WHO Criteria for Diagnosis of Osteoporosis. Available at: http://www.4bonehealth.org/education/world-healthorganization-criteria-diagnosis-osteoporosis. Accessed January 25, 2016.

36. Puri A, Shah M, Agarwal MG, Jambhekar NA, Basappa P. Chondrosarcoma of bone: does the size of the tumor, the presence of a pathologic fracture, or prior intervention have an impact on local control and survival? J Cancer Res Ther. 2009;5:14-19.

37. Riedel RF, Larrier N, Dodd L, Kirsch D, Martinez S, Brigman BE. The clinical management of chondrosarcoma. Curr Treat Options Oncol. 2009;10:94-106.

38. Ruza E, Sierrasesúmaga L, Azcona C, Patiño-Garcia A. Bone mineral density and bone metabolism in children treated for bone sarcomas. Pediatr Res. 2006;59:866-871.

39. Siris ES, Miller PD, Barrett-Connor E, Faulkner KG, Wehren LE, Abbott TA, Berger ML, Santora AC, Sherwood LM. Identification and fracture outcomes of undiagnosed low bone mineral density in postmenopausal women: results from the National Osteoporosis Risk Assessment. JAMA. 2001;286:2815-2822.

40. Tenardi RD, Frühwald MC, Jürgens H, Hertroijs D, Bauer J. Nutritional status of children and young adults with Ewing sarcoma or osteosarcoma at diagnosis and during multimodality therapy. Pediatr Blood Cancer. 2012;59:621-626.

41. Urbas E. Gesundheitszustand \& Konsum medizinischer Leistungen: Ergebnisse des Mikrozensus September 1999. Wien, Austria: Statistik Austria; 2002.

42. Walker RE, Lawson MA, Buckle CH, Snowden JA, Chantry AD. Myeloma bone disease: pathogenesis, current treatments and future targets. Br Med Bull. 2014;111:117-138.

43. Walter JH, Peacock D, Powell A. Myxoid chondrosarcoma-induced pathologic fracture. J Am Podiatr Med Assoc. 1994;84: 411-413. 